\title{
Strong motion generation area modelling of the 2008 Iwate earthquake, Japan using modified semi-empirical technique
}

\author{
Sandeep $^{1}$, A Joshi ${ }^{2}$, Sonia Devi ${ }^{1}$, Parveen Kumar ${ }^{3, *}$, S K SaH ${ }^{1}$, \\ SOHAN LAL ${ }^{2}$ and KAMAL ${ }^{2}$ \\ ${ }^{1}$ Department of Geophysics, Banaras Hindu University, Varanasi 221 005, India. \\ ${ }^{2}$ Department of Earth Sciences, Indian Institute of Technology Roorkee, Roorkee, India. \\ ${ }^{3}$ Wadia Institute of Himalayan Geology, Dehradun, India. \\ *Corresponding author.e-mail: sainiparveen.saini@gmail.com
}

MS received 23 October 2018; revised 30 March 2019; accepted 10 May 2019

The Iwate-Miyagi earthquake $\left(M_{\mathrm{w}} 6.9\right)$ of 14 June 2008 is one of the largest intraplate earthquakes that struck north-east Japan. This earthquake has produced the largest peak ground acceleration (PGA) ever recorded. The acceleration values 4022 and 1036 gal were observed at the surface and borehole accelerometers of IWTH25. To understand the cause of this extremely large acceleration, it is highly essential to obtain the detailed rupture process of Iwate-Miyagi earthquake. The present paper estimates the rupture model for this earthquake using the modified semi-empirical technique (MSET). The detailed analysis proposes one strong motion generation area (SMGA) in the rupture plane and nucleation point in the extreme western corner of the SMGA. Using this estimated source model, a satisfactory match is observed between the simulated and actual records. The quantitative analysis of these waveforms provides an almost 1:1 match for PGA values. Furthermore, the variation of these PGA values with epicentral distance shows similar attenuation rate. These results confirm the reliability of MSET and the estimated source model of this earthquake. To the best of our knowledge, this study is the first to model SMGAs in the rupture model using MSET and provides sufficiently reliable information which will be useful for seismic hazard prevention management.

Keywords. 2008 Iwate-Miyagi earthquake; semi-empirical; SMGA; high-frequency records.

\section{Introduction}

The 2008 Iwate-Miyagi earthquake $\left(M_{\mathrm{w}} 6.9\right)$ was a reverse-fault-type crustal earthquake that occurred in the central portion of north-east (NE) Japan on 14 June 2008. Table 1 illustrated the earthquake parameters. This earthquake caused 23 casualties, 450 injuries and damaged about 2000 houses. This earthquake produced the largest peak ground acceleration (PGA) at IWTH25 Published online: 22 July 2019 station located just above the hypocentre. To clarify the cause of this extremely large acceleration, it is vitally important to obtain the detailed rupture process of the Iwate-Miyagi earthquake. This detailed rupture analysis will be useful for modelling future earthquake and policy development for seismic hazard assessment and risk reduction.

In recent years, strong motion simulation techniques have been emerged as efficient and powerful 
Table 1. Mainshock parameters of the 2008 Iwate-Miyagi earthquake.

\begin{tabular}{lclc}
\hline Origin time, location, depth & Size source & Fault plane solution & Reference \\
\hline $23: 43: 53.2(\mathrm{GMT}), 39.03^{\circ} \mathrm{N}$ & $M_{0}=2.58 \times 10^{19} \mathrm{~N} \mathrm{~m}, M_{\mathrm{w}}=6.9$ & $\mathrm{NP} 1: \phi=17^{\circ}, \delta=42^{\circ}, \lambda=87^{\circ}$ & Global CMT \\
$140.85^{\circ} \mathrm{E}, 12 \mathrm{~km}$ & & $\mathrm{NP} 2: \phi=201^{\circ}, \delta=48^{\circ}, \lambda=92^{\circ}$ & Harvard \\
\hline
\end{tabular}

tools in designing earthquake-resistant structures in seismically active regimes. As a consequence, numerous authors including Miyake et al. (1999, 2001, 2003), Kamae and Kawabe (2004), Miyahara and Sasatani (2004), Suzuki and Iwata (2007), Kurahashi and Irikura (2011), Takiguchi et al. (2011) and Asano and Iwata (2012) have employed empirical Green's function (EGF) technique to simulate high-frequency records using strong motion generation areas (SMGAs) in the rupture plane. Although the EGF technique is the most dependable one, the requirement of an aftershock event has created a bottleneck. In the above light, the semi-empirical technique would be of great significance as it does not require aftershock records and utilises empirically generated envelope function to simulate strong motion records (Midorikawa 1993). The efficacy of the above technique has been successfully established for 1985 Central Chile earthquake $\left(M_{\mathrm{s}} 7.8\right), 1986$ Dharmsala $\left(M_{\mathrm{s}} 5.3\right)$ and

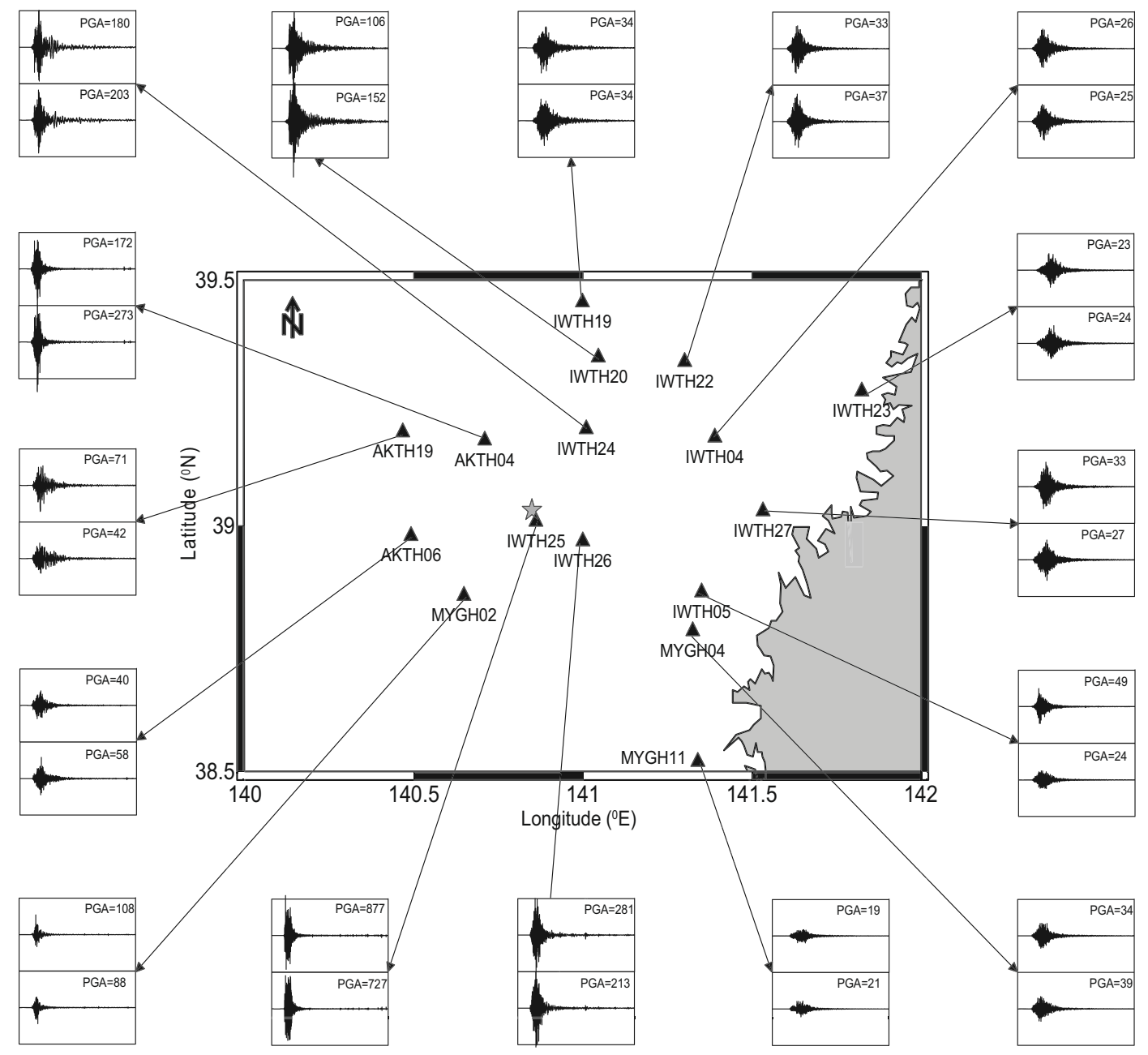

Figure 1. Processed NS and EW components of observed acceleration records at 16 different stations IWTH25, IWTH26, AKTH04, IWTH24, MYGH02, AKTH06, IWTH20, AKTH19, IWTH05, IWTH04, MYGH04, IWTH19, IWTH22, IWTH27, MYGH11 and IWTH23 used for simulation. Star represents the epicentre of mainshock and the triangles show the location of the stations (map after Suzuki et al. 2010). 


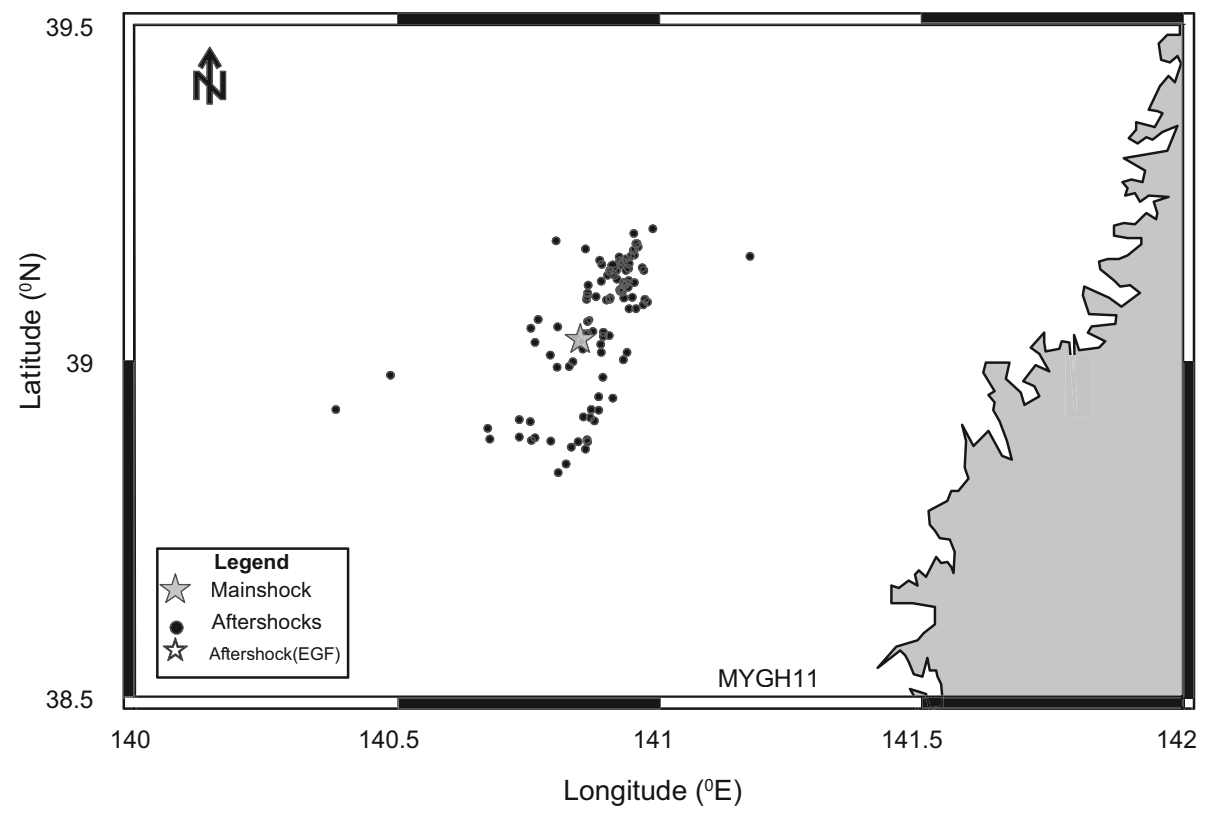

Figure 2. Spatial distributions of 105 aftershock events recorded on KiK-net, K-NET and USGS network stations. Star represents the mainshock location. Solid circles represent the 105 aftershocks of the event (map after Suzuki et al. 2010).

(a)

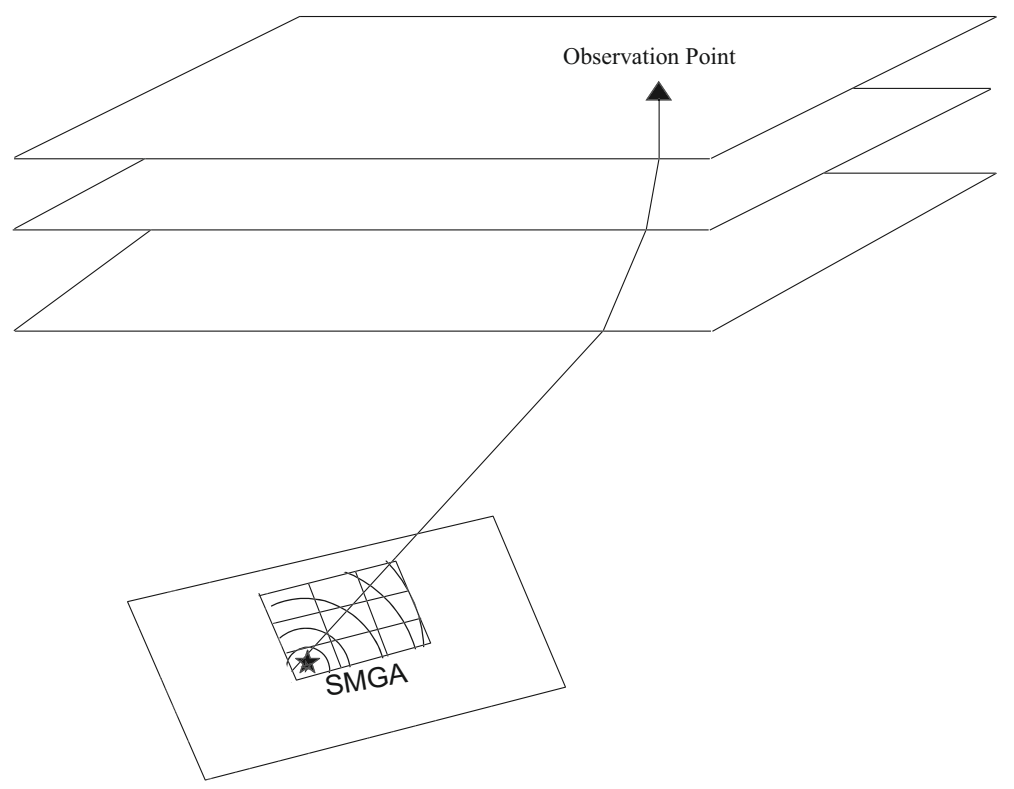

(b)
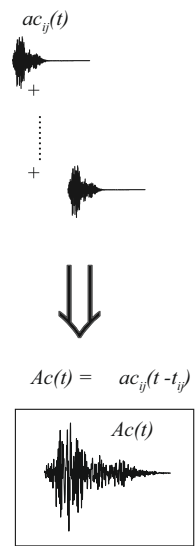

Figure 3. (a) Rupture model in a layered earth medium. Star and triangle denote the nucleation point of identified SMGA and observation point, respectively. (b) Summation of the records from each subfault of SMGA to simulate the acceleration record of the target earthquake.

1991 Uttarkashi earthquake $\left(M_{\mathrm{s}} 6.7\right)$. Later on, Joshi et al. (2014) modified the semi-empirical technique to consider only SMGAs instead of the whole rupture plane for strong motion simulation. This modification significantly improved the applicability of the semi-empirical technique for the estimation of ground-motion characteristics. In continuation of our growing interest in the modified semi-empirical technique (MSET), we herein demonstrate the applicability of MSET for the 2008 Iwate-Miyagi earthquake.

\section{Motivation}

As we previously mentioned the IWTH25 station of KiK-net (National Institute for Educational Development), situated $3 \mathrm{~km}$ south-west of the 


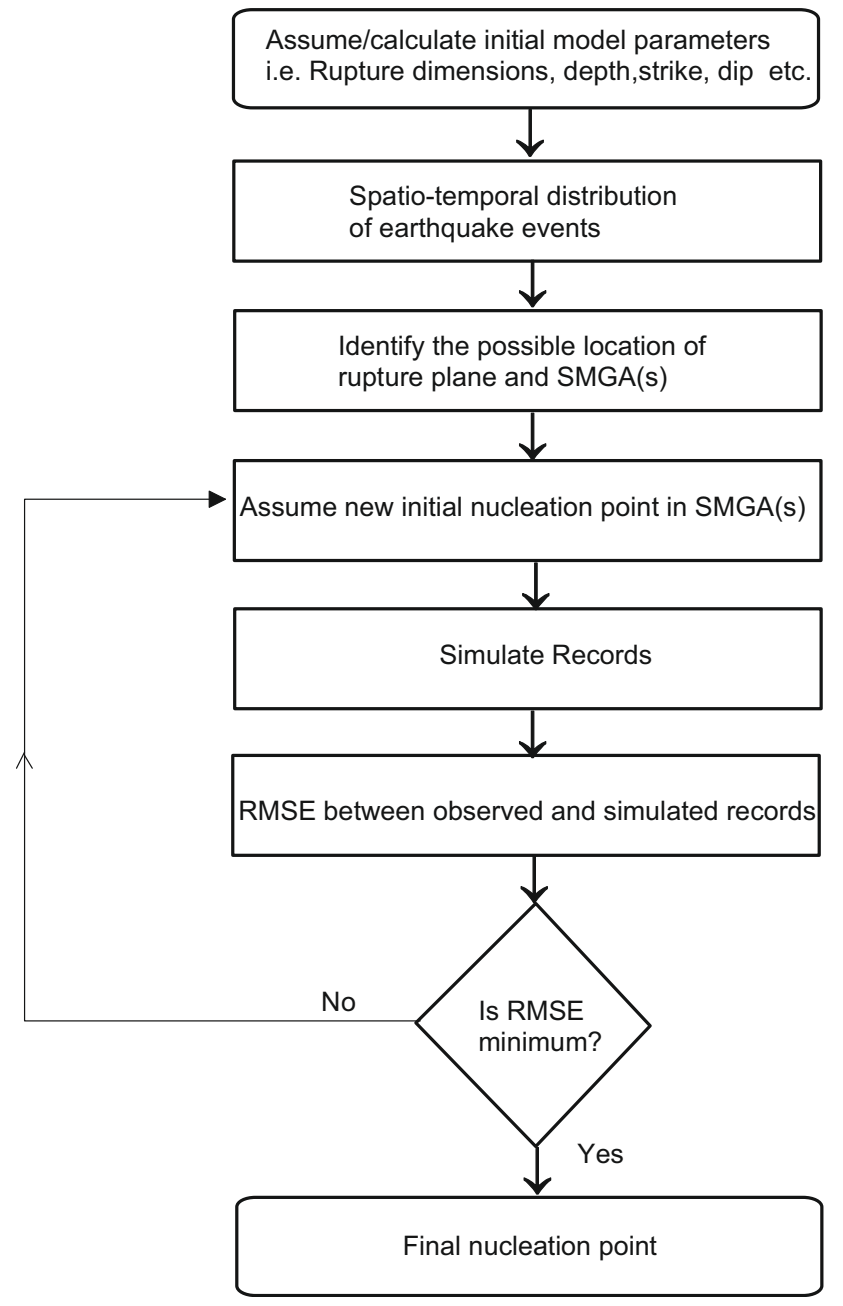

Figure 4. Flowchart illustrating the methodology for the simulation of strong motion records.

epicentre, observed the largest PGA value during an earthquake. These outcomes inspired us to derive the detailed rupture process of the IwateMiyagi earthquake. The above analysis will be useful for the development of a policy for seismic hazard assessment and risk reduction. Furthermore, this will provide an in-depth knowledge on the source characteristics of this earthquake, which will be useful for modelling future earthquakes in this region. To fulfil the above aim, the strong motion records at 16 proximal stations of KiK-net are used to estimate the ground-motion characteristics of the Iwate region. Primarily, this research work has been focused on the reliability of the MSET to estimate the source model of the Iwate-Miyagi earthquake. The simulated records will provide a detailed analysis of regional peculiarities of ground motion excitation and propagation and therefore upgrades the various approaches of seismic hazard analysis.

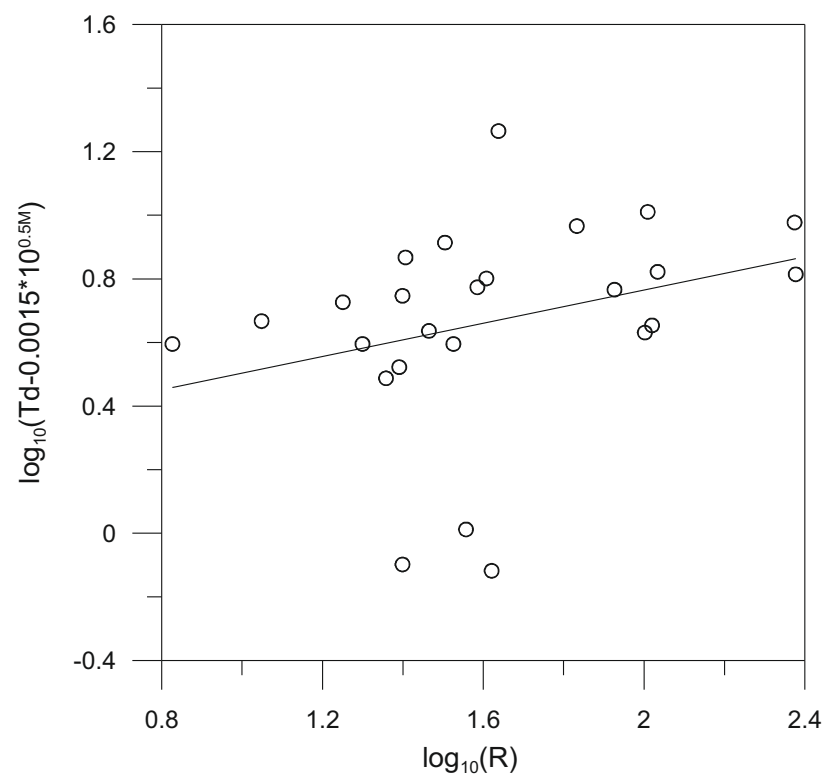

Figure 5. Plot for duration parameter $\left(T_{\mathrm{d}}\right)$ estimated from the acceleration records of the 2008 Iwate-Miyagi earthquake.

\section{Data}

The 2008 Iwate-Miyagi earthquake was recorded at 655 stations of Kyoshin (K-NET) and Kiban Kyoshin network (KiK-net) installed across Japan. The acceleration data from 16 near-field stations with epicentral distance between 3 and $86 \mathrm{~km}$ was used (figure 1). In particular, we employed the strong motion data produced at KiK-net borehole stations, which are less influenced by heterogeneous subsurface structures near the ground surface. Initially, recorded data were processed for instrument scaling. Instrument scaling converts counts/volt recorded by instruments into actual ground motion. Different instruments have different scaling factors and based on the type of sensor, different values of the scaling factor are proposed for different data. In the present study, data recorded by KiK-net borehole stations were corrected with scaling factor 2940/6170270. The other major problem with accelerograms is distortions and shifts of the reference baseline. In the present study, this distortion was removed by applying baseline correction to the recorded data. Finally, to remove low- and high-frequency noise, a fourthorder band pass butterworth filter was applied to the data. Low cut was selected as $0.01 \mathrm{~Hz}$ by the visual inspection of the integrated acceleration time series (Boore and Bommer 2005). The high cut was maintained at $10 \mathrm{~Hz}$ in view of the range of interest for earthquake-resistant design. The whole 
(a)

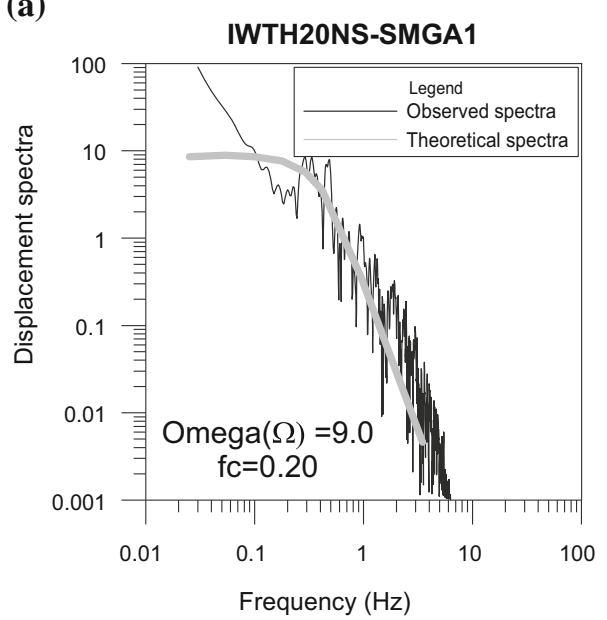

(b)

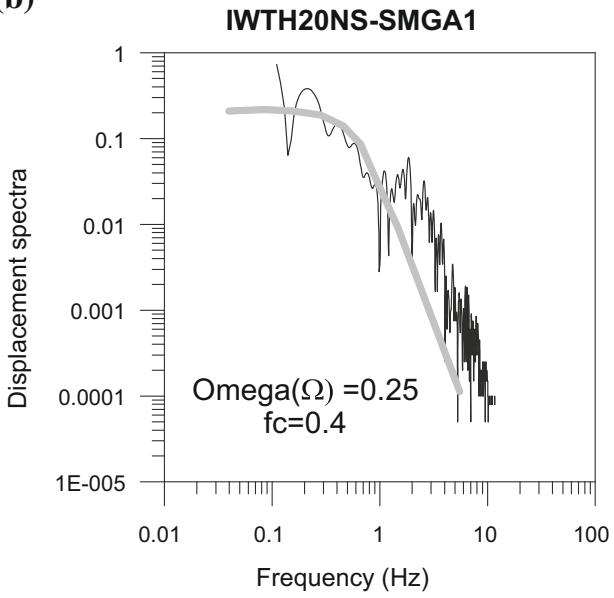

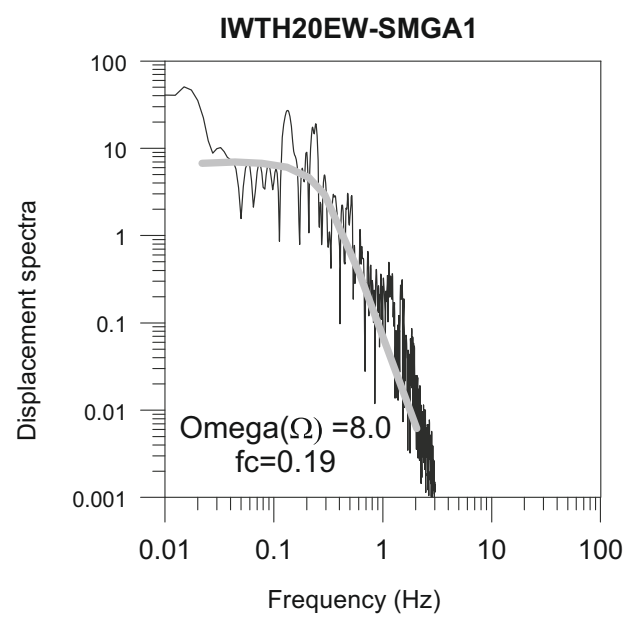

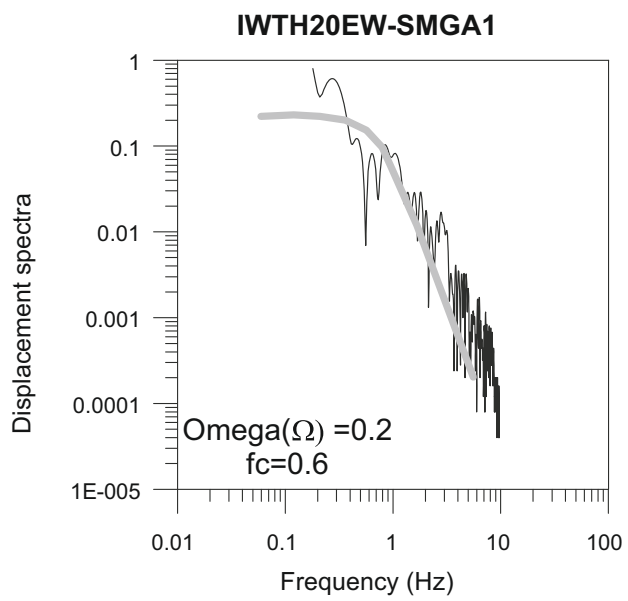

Figure 6. Theoretical (grey) and observed (black) displacement spectra of recorded acceleration (mainshock and aftershock) for NS and EW component at IWTH20 station.

Table 2. Average values of source parameters calculated from source displacement spectra of mainshock and aftershock at IWTH20 station.

\begin{tabular}{lcccr}
\hline & $\begin{array}{c}\text { Corner } \\
\text { frequency } \\
f_{\mathrm{c}}\end{array}$ & $\begin{array}{c}\text { Flat level } \\
\text { spectrum }\end{array}$ & $\begin{array}{c}\text { Seismic } \\
\text { moment }\end{array}$ & $\begin{array}{c}\text { Stress } \\
\text { drop }\end{array}$ \\
Event & $(\mathrm{Hz})$ & $(\mathrm{m} \mathrm{s})$ & $\begin{array}{c}M_{0} \\
(\mathrm{~N} \mathrm{~m})\end{array}$ & $\begin{array}{c}\Delta \sigma \\
(\mathrm{Pa})\end{array}$ \\
\hline Mainshock & 0.195 & 8.5 & $2.61 \times 10^{18}$ & $60,97,000$ \\
Aftershock & 0.5 & 0.225 & $6.91 \times 10^{16}$ & 272,000 \\
\hline
\end{tabular}

processing of the recorded data was carried out using the Seismosignal software, Seismosoft (2002).

Along with this mainshock event, we also used a total of 105 aftershock events that were recorded at USGS, K-NET and KiK-net, stations during a 16-day period from 14 June 2008 to 1 July 2008 in the present study (figure 2). The spatio-temporal distribution of these aftershocks revealed an approximate NW trend of the events.

Table 3. Aftershock parameters of the 2008 Iwate-Miyagi earthquake.

\begin{tabular}{lllc}
\hline Hypocentre & Size & Fault plane solution & Reference \\
\hline 14 June 2008 & $M_{\mathrm{o}}=1.79 \times 10^{16} \mathrm{~N} \mathrm{~m}, M_{\mathrm{w}}=4.8$ & $\mathrm{NP} 1: \phi=210^{\circ}, \delta=34^{\circ}, \lambda=93^{\circ}$ & Global CMT \\
$14: 42: 34.5 \mathrm{GMT}$ & & $\mathrm{NP} 2: \phi=27^{\circ}, \delta=57^{\circ}, \lambda=88^{\circ}$ & Harvard \\
$39.05^{\circ} \mathrm{N}, 140.94^{\circ} \mathrm{E}$ & & & \\
$17.3 \mathrm{~km}$ & & & \\
\hline
\end{tabular}




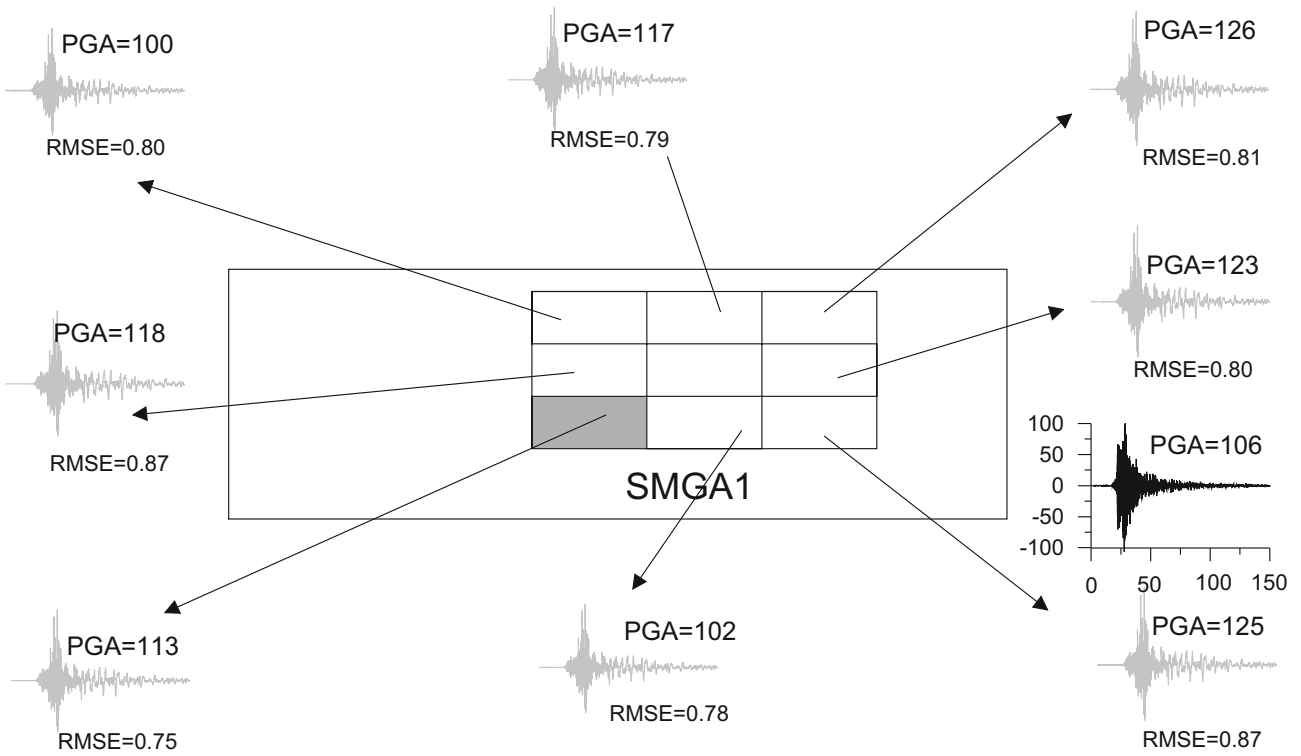

Figure 7. Observed (black) and simulated (grey) records at IWTH20 station for different nucleation points. Location of final nucleation point corresponding to minimum RMSE.

Table 4. Parameters of the SMGA used for final simulation.

\begin{tabular}{lll}
\hline SMGA & SMGA & \multicolumn{1}{c}{ References } \\
\hline Length $(\mathrm{km})$ & 18.0 & Wells and Coppersmith (1994) \\
Width $(\mathrm{km})$ & 9.0 & Wells and Coppersmith (1994) \\
No. of subfaults & $3 \times 3$ & Scaling relation (Kanamori \\
$(N \times N)$ & & and Anderson 1975) \\
Strike & $201^{\circ}$ & CMT Harvard \\
Dip & $48^{\circ}$ & CMT Harvard \\
\hline
\end{tabular}

\section{Methodology}

In this study, we employed MSET to simulate strong motion records of the 2008 Iwate-Miyagi earthquake. As we previously mentioned, it is an improved version of the semi-empirical technique pioneered by Midorikawa (1993) to estimate strong motion characteristics. Multiple researchers employed the above technique to simulate strong motion

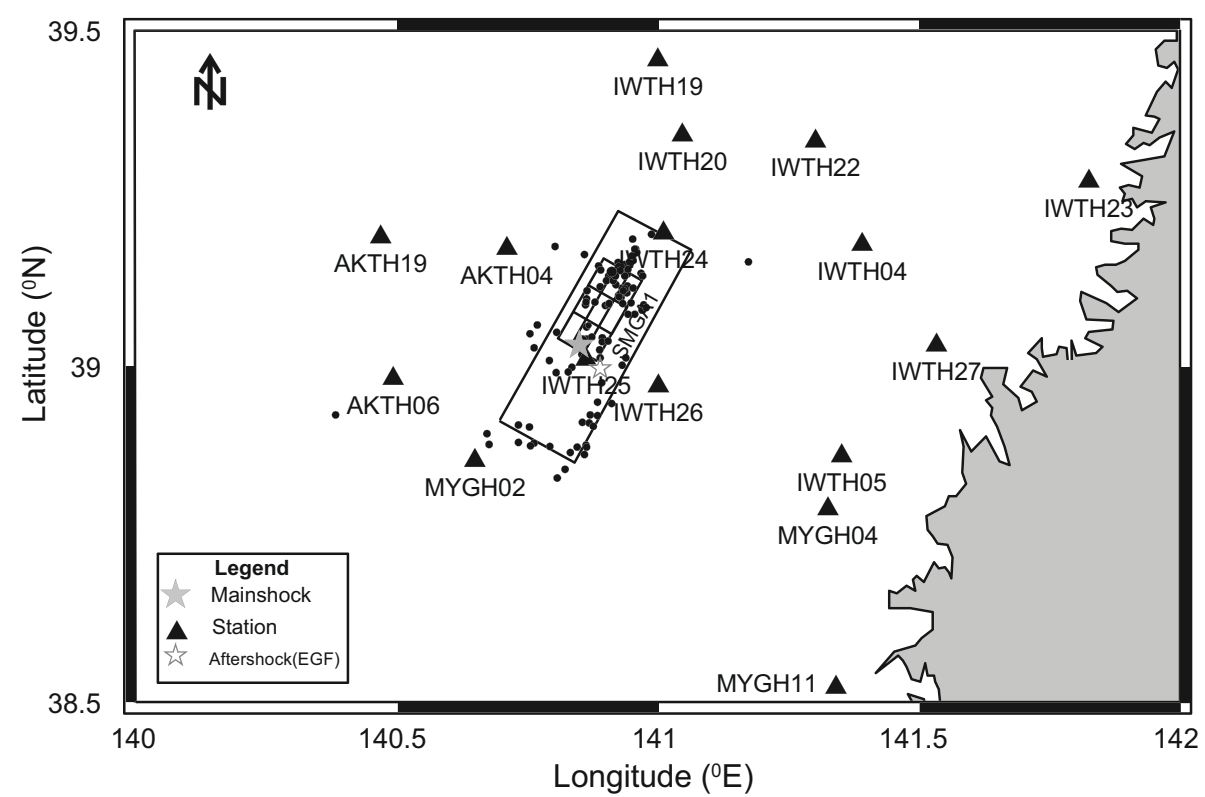

Figure 8. Source model of the 2008 Iwate-Miyagi earthquake $\left(M_{\mathrm{w}} 6.9\right)$ showing one SMGA within the rupture plane. Solid circles show the aftershock distribution within the region. The solid star represents the epicentre of the earthquake and solid triangles indicate the strong motion stations (map after Suzuki et al. 2010). 
records (Joshi and Patel 1997; Kumar et al. 1997; Joshi et al. 1999, 2001, 2012a, b, 2014, 2015; Joshi 2001, 2004; Joshi and Midorikawa 2004; Sandeep et al. 2014a, b, 2015, 2017a, b, c, 2019; Kumar et al. 2016). In this technique, the rupture plane of the target earthquake is divided into grid of equal sizes known as subfaults. It is worth mentioning that the above division follows the self-similarity laws proposed by Aki (1967) which later on were modified by Kanamori and Anderson (1975). For each subfault, Boore (1983) has described the acceleration spectra $A(f, R)$ as follows:

$$
A(f, R)=C S(f) D(f) F(f, R),
$$

where $C$ is the constant scaling factor; $S(f)$ is the source acceleration spectrum (Brune 1970); $D(f)$ is the

Table 5. Velocity model (Ukawa et al. 1984) used for studying source model.

\begin{tabular}{lcc}
\hline $\begin{array}{l}\text { Depth } \\
(\mathrm{km})\end{array}$ & $\begin{array}{c}V_{\mathrm{s}} \\
(\mathrm{km} / \mathrm{s})\end{array}$ & $\begin{array}{c}\text { Density } \\
\left(\mathrm{kg} / \mathrm{m}^{3}\right)\end{array}$ \\
\hline 0 & 3.26 & 2400 \\
2 & 3.30 & 2600 \\
6 & 3.35 & 2600 \\
10 & 3.40 & 2600 \\
14 & 3.45 & 2600 \\
10 & 3.49 & 2600 \\
12 & 3.54 & 2600 \\
14 & 3.59 & 2600 \\
\hline
\end{tabular}

high frequencies attenuation which is mainly controlled by $f_{\max }$ (high-frequency cut-off range of the high-cut filter) and $F(f, R)$ is the attenuation factor (Boore 1983).

To generate the acceleration spectra, Boore (1983) utilised the multiplication of theoretical filters with the spectrum of band-limited finite duration white Gaussian noise. The obtained acceleration spectra for each subfault correspond to the acceleration records in time domain and require further correction for the difference in slip duration of the target and small earthquake (subfaults). As a consequence, the corrected acceleration record $A_{i j}(t)$ is generated by convolving the earlier simulated records $a_{i j}(t)$ with the correction function $F(t)$ (Irikura and Kamae 1994; Irikura et al. 1997) and is expressed as

$$
A_{i j}(t)=F(t) * a_{i j}(t) .
$$

Here $F(t)$ stands for the correction function and is represented as

$$
\begin{aligned}
F(t)= & \delta(t)+\left[(N-1) / T_{\mathrm{R}}(1-\exp (-1))\right] \\
& \times \exp \left(-t / T_{\mathrm{R}}\right),
\end{aligned}
$$

where $i, j$ refer to the subfault position along the rupture length and width, respectively, $N$ denotes the total number of subfaults rupture length or width, $\delta(t)$ is the delta function and $T_{\mathrm{R}}$ is the rise time.

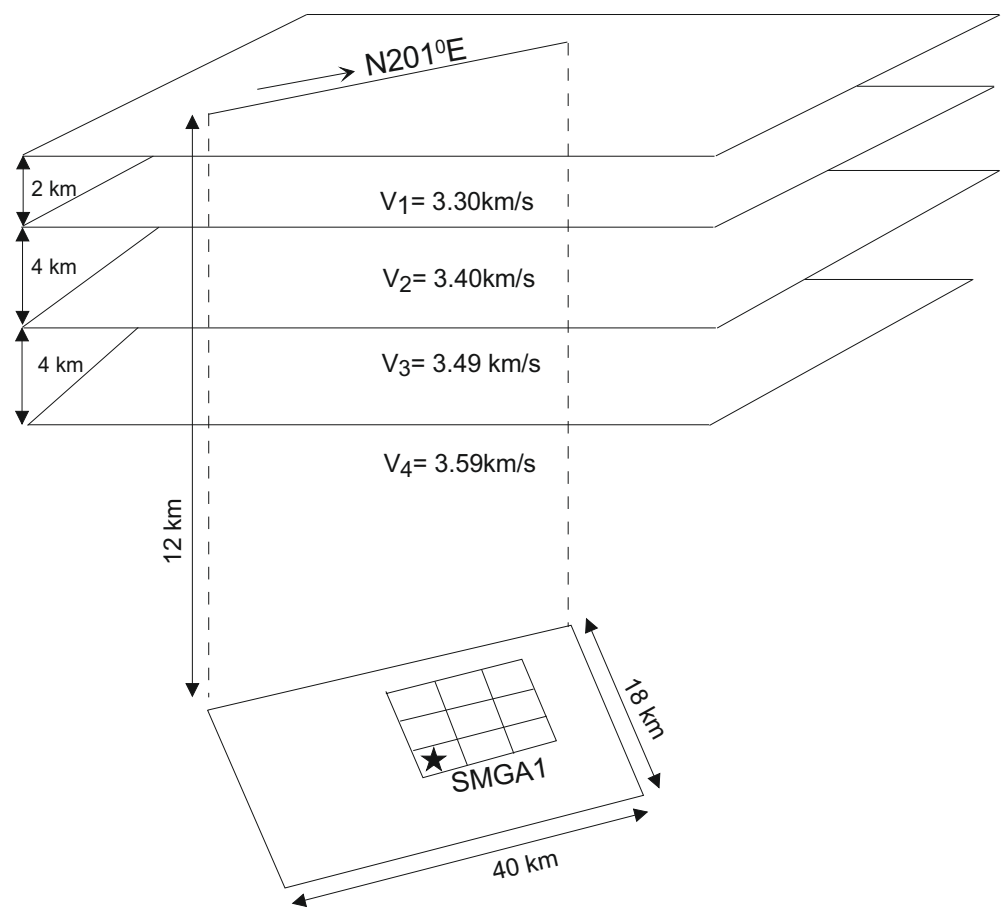

Figure 9. Four layer velocity model used for simulation of the Iwate-Miyagi earthquake (Ukawa et al. 1984). Rupture with $\mathrm{N} 201^{\circ} \mathrm{E}$ strike direction and $48^{\circ}$ dip is placed in the fourth layer of the medium. 

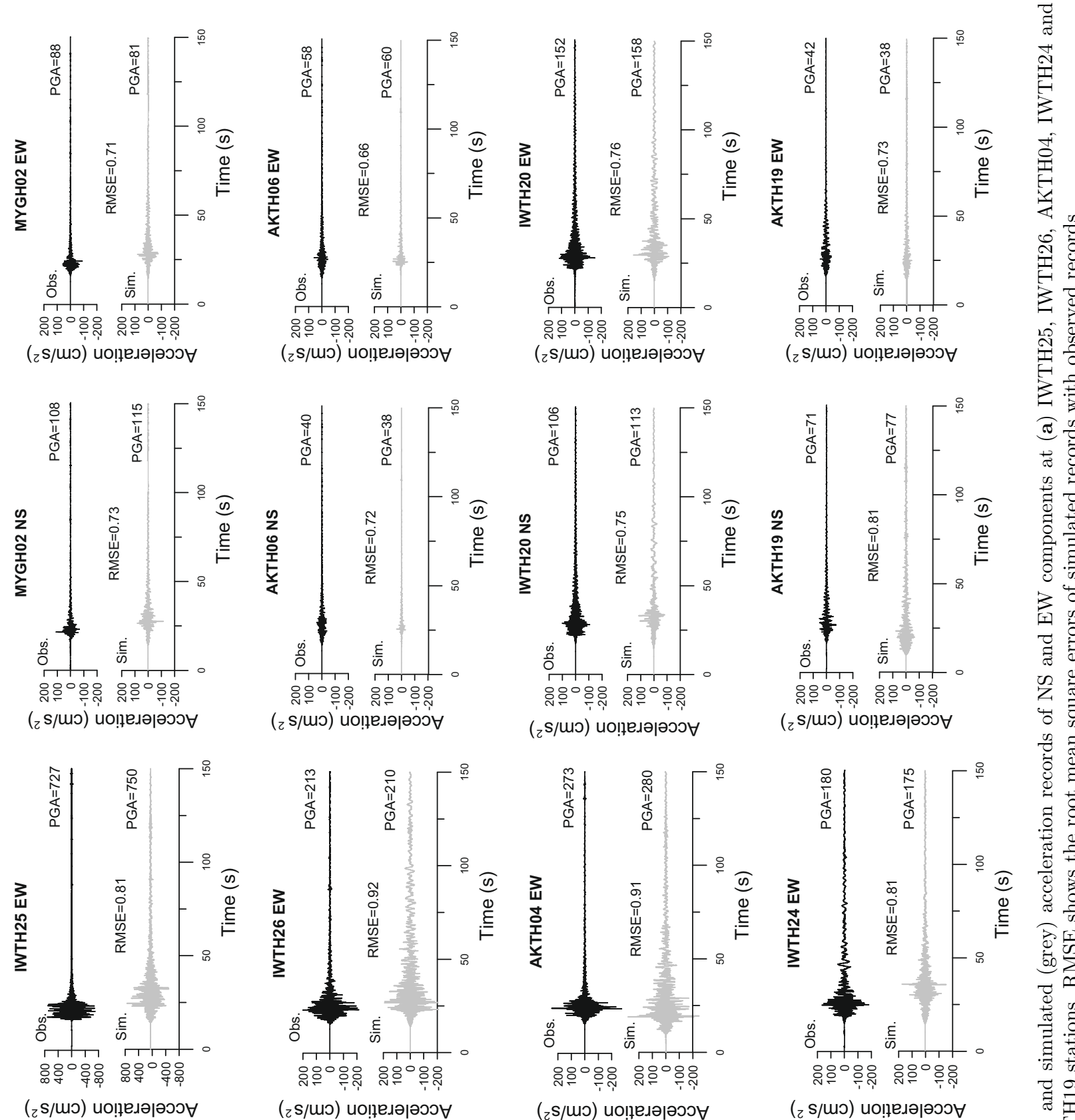

(

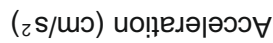

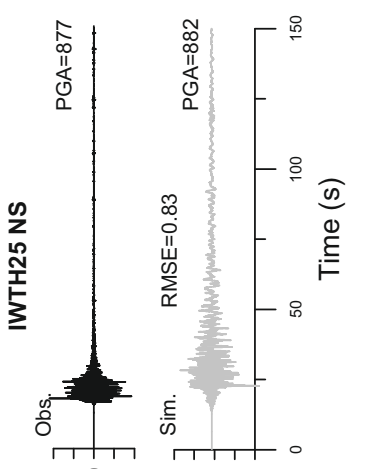

త్ర

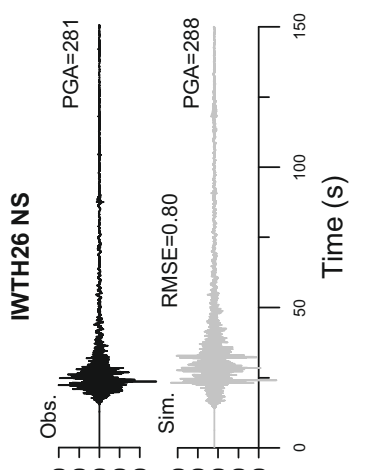

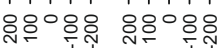

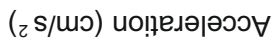

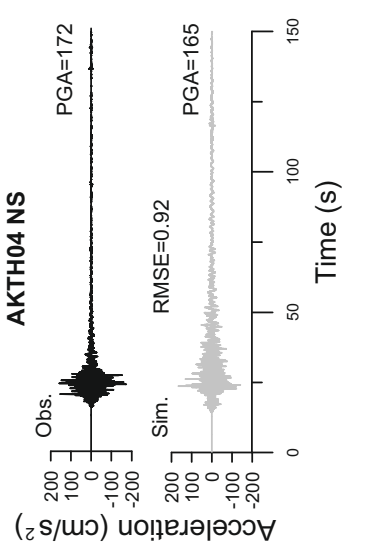

范芭

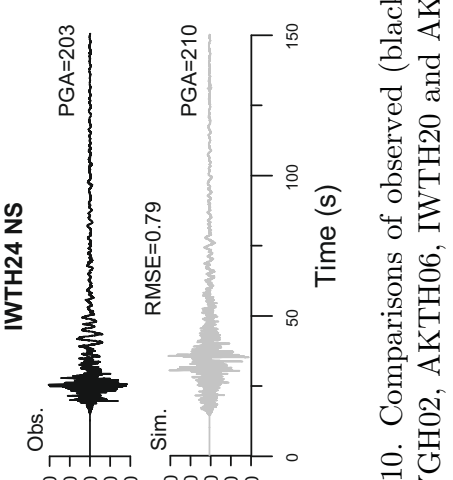

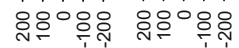

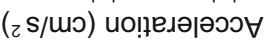




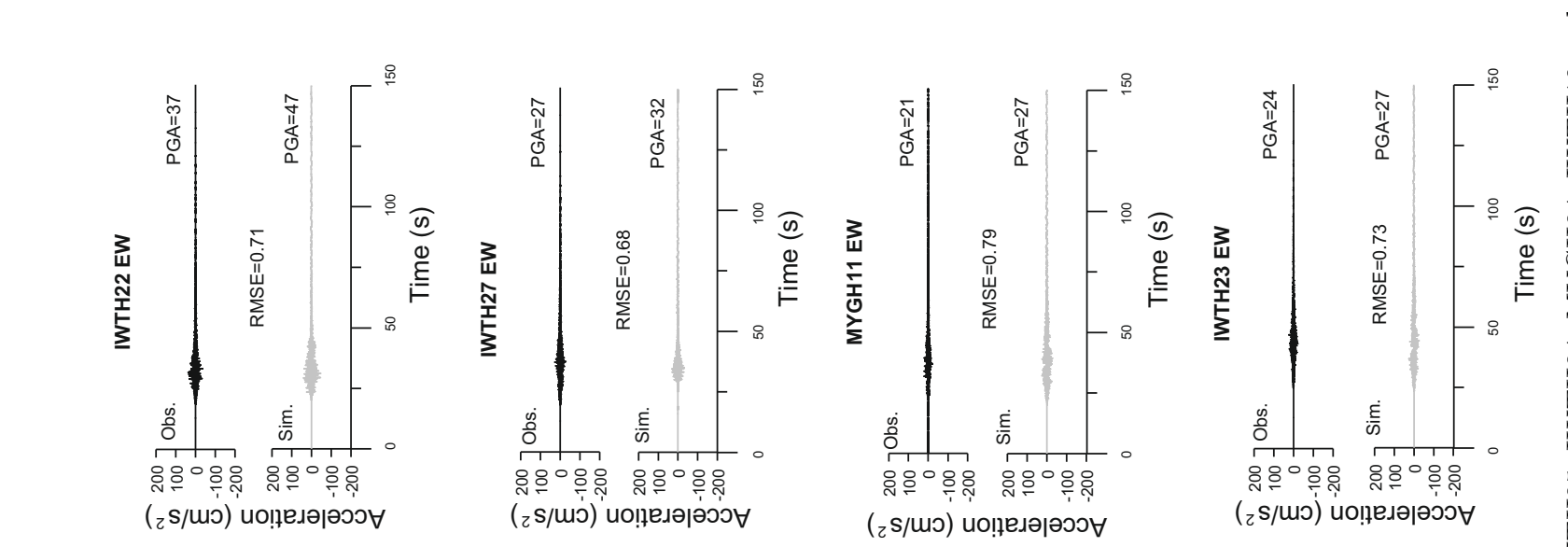

ซี

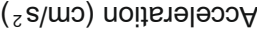
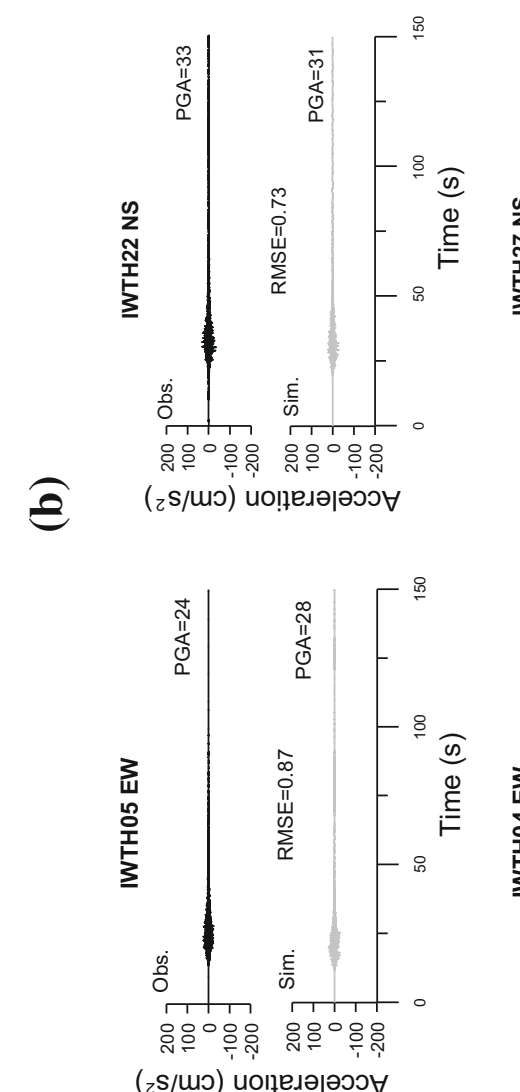
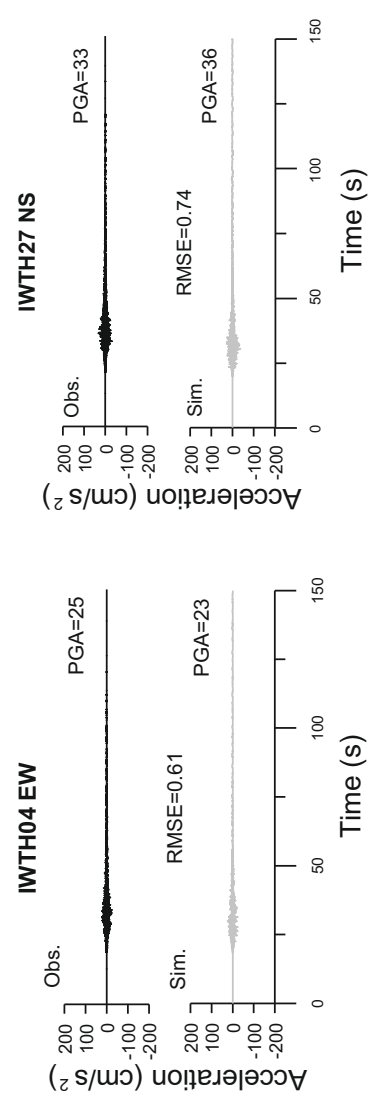

( ${ }_{z} \mathrm{~s} / \mathrm{u \nu}$ ) ио!̣едәрәоว

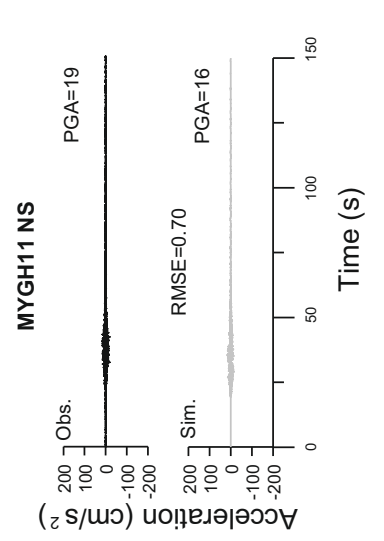

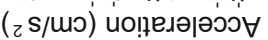

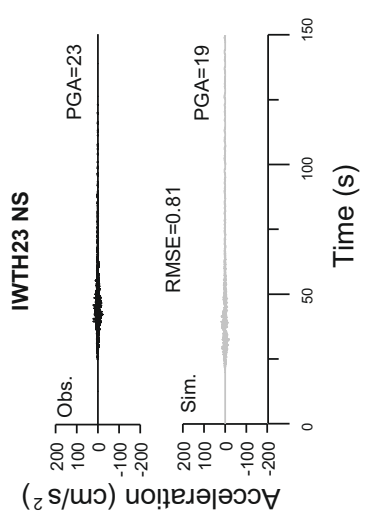

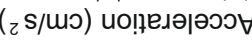
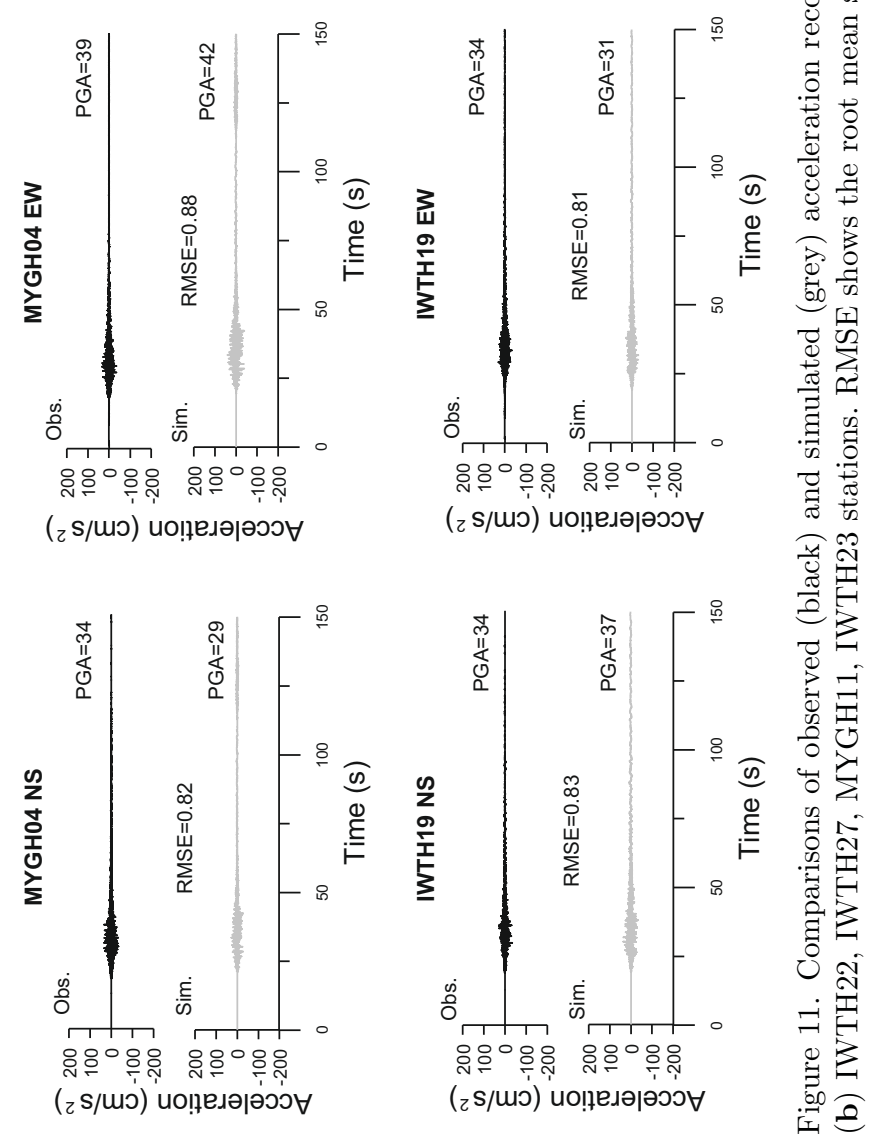
(a)
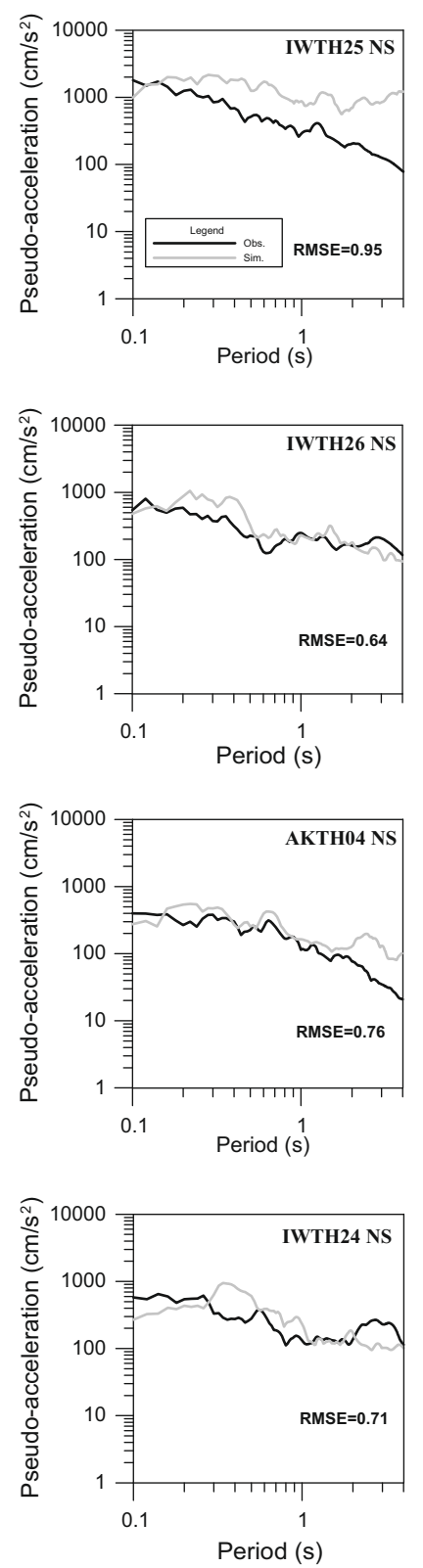
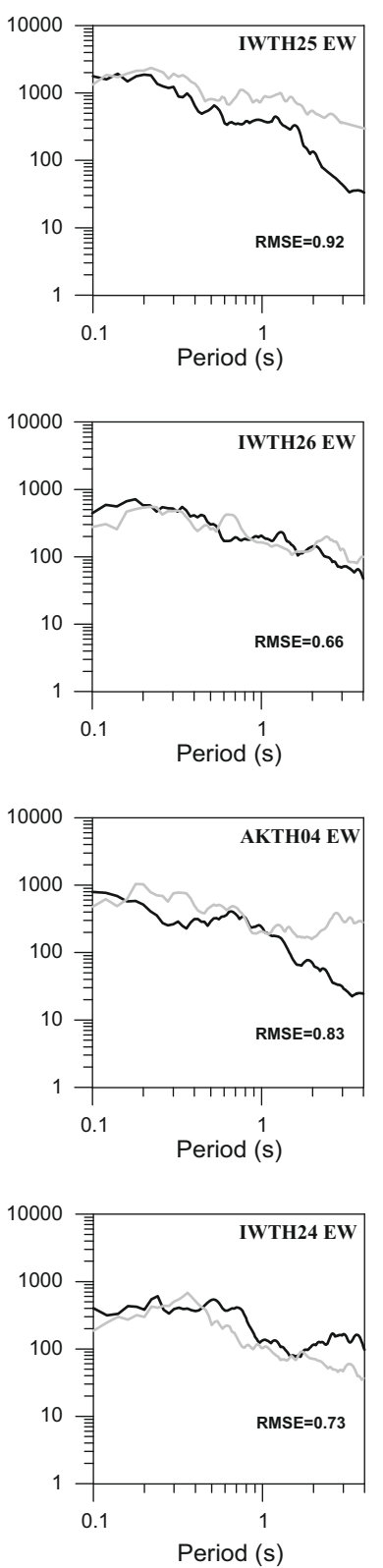

(b)
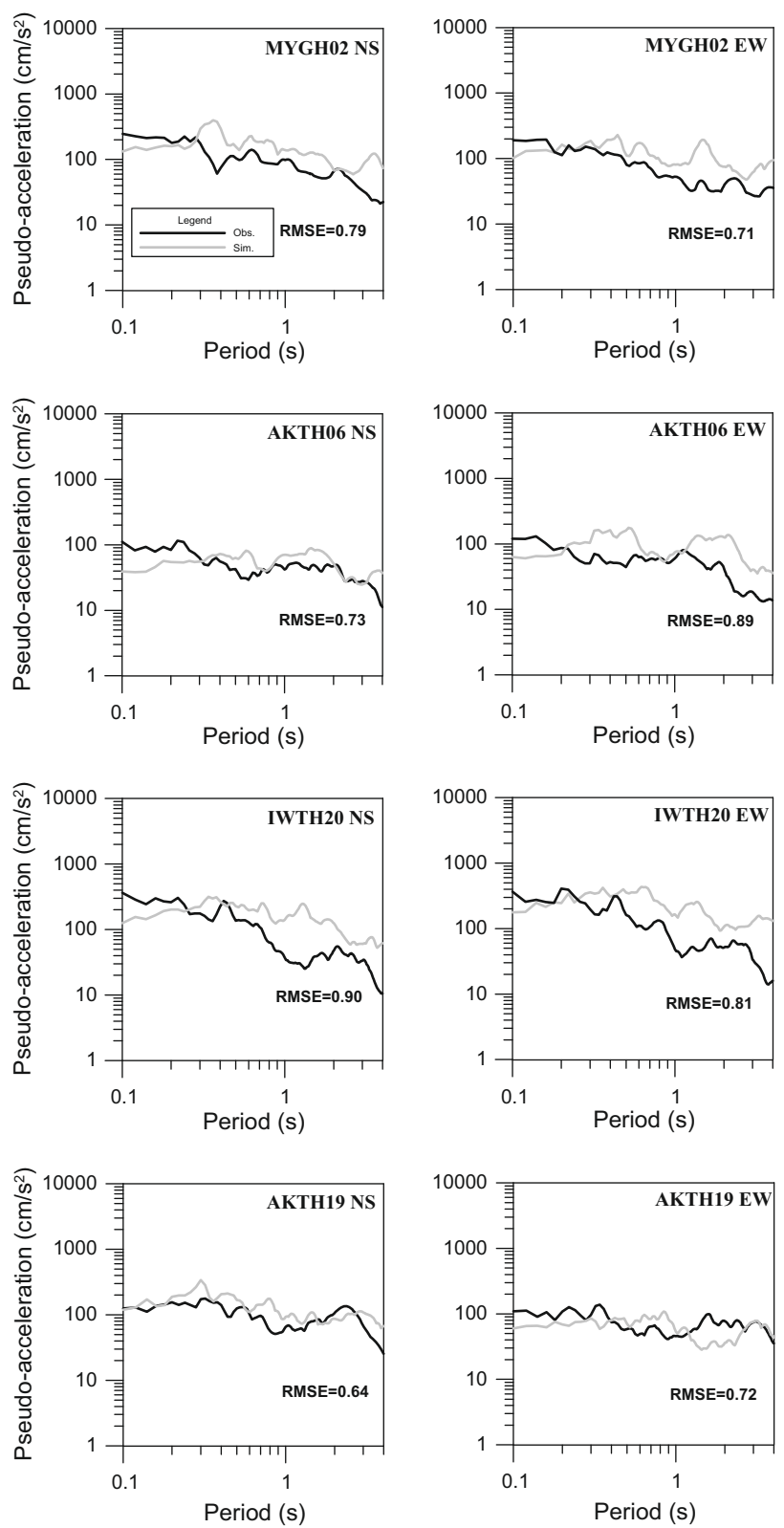

Figure 12. Comparisons of pseudo-acceleration response spectra calculated from observed (black) and simulated (grey) acceleration record of NS and EW components at (a) IWTH25, IWTH26, AKTH04, IWTH24 and (b) MYGH02, AKTH06, IWTH20 and AKTH19 stations. RMSE shows the root mean square errors of simulated records with observed records.

This semi-empirical technique demands appropriate windowing of the corrected simulated records. Relevant to this, Kameda and Sugito (1978) have proposed the functional form of the acceleration envelope $e_{i j}(t)$ and further modified by Joshi in 2004 . Following their modification, the final acceleration record $\mathrm{ac}_{i j}(t)$ has been generated by the multiplication of the corrected simulated acceleration record with the envelope function as follows:

$$
\operatorname{ac}_{i j}(t)=e_{i j}(t) \cdot A_{i j}(t)
$$

where $e_{i j}(t)$ is the envelope function and is represented as

$$
e_{i j}(t)=T_{\mathrm{ss}}\left(t / T_{\mathrm{d}}\right) \cdot \exp \left(1-t / T_{\mathrm{d}}\right),
$$

where $T_{\mathrm{d}}$ and $T_{\mathrm{ss}}$ are the duration parameter and transmission coefficient, respectively.

The summation of all acceleration record $\mathrm{ac}_{i j}(t)$ from the individual subfault arriving at an observation point with time shift $t_{i j}$ generates the final simulated acceleration record $\mathrm{Ac}(t)$ for the target event as follows: 
(a)
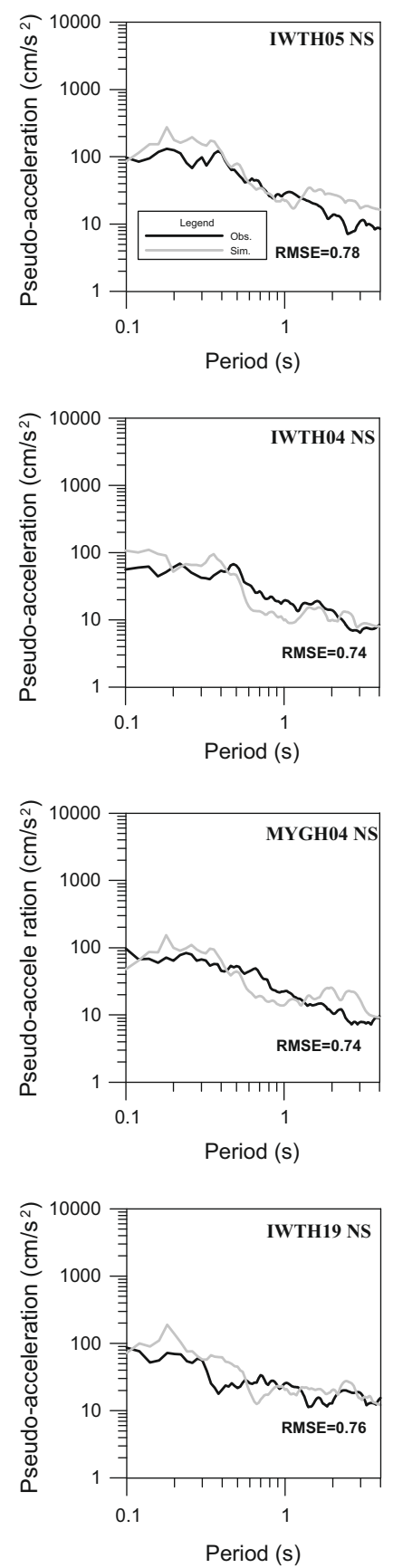
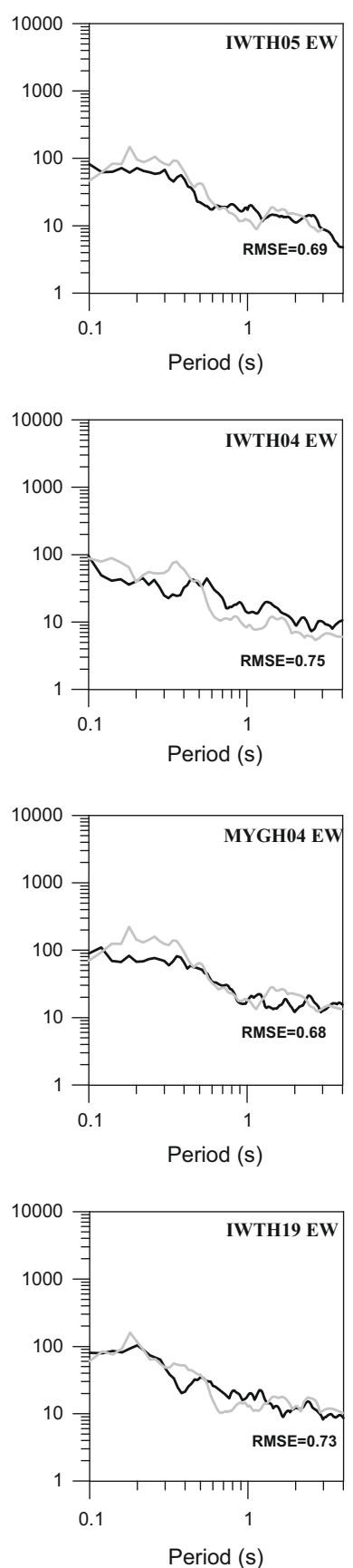

(b)
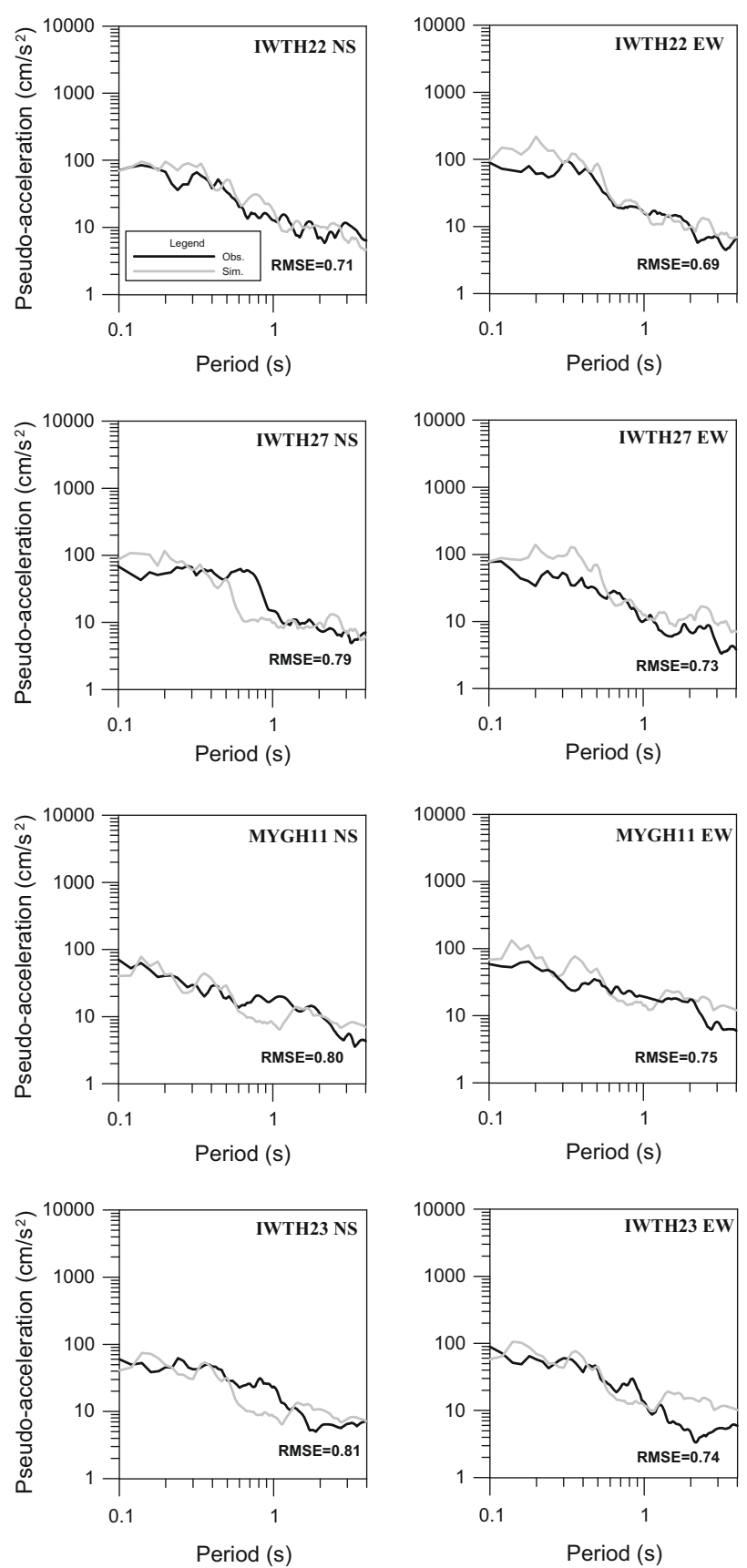

Figure 13. Comparisons of pseudo-acceleration response spectra calculated from observed (black) and simulated (grey) acceleration record of NS and EW components at (a) IWTH05, IWTH04, MYGH04, IWTH19 and (b) IWTH22, IWTH27, MYGH11, IWTH23 stations. RMSE shows the root mean square errors of simulated records with observed records.

$$
\operatorname{Ac}(t)=\sum_{i=1}^{N} \sum_{j=1}^{N} \operatorname{ac}_{i j}\left(t-t_{i j}\right) .
$$

In the MSET, we considered only the contribution of identified SMGA towards strong ground motion instead of the entire rupture plane. In the present study, we modelled an SMGA in the rupture plane of the 2008 Iwate-Miyagi earthquake using
MSET (figure 3). The above methodology is also described in the form of a flowchart (figure 4).

\section{Scaling laws}

The MSET relies on various region-specific parameters such as the duration parameter $\left(T_{\mathrm{d}}\right)$ and the quality factor, $Q(f)$, of the region. The duration 
Table 6. Matching details between observed and simulated PGA, and response spectra at different stations.

\begin{tabular}{|c|c|c|c|c|}
\hline Station & $\begin{array}{l}\text { Epicentral } \\
\text { distance } \\
(\mathrm{km})\end{array}$ & $\begin{array}{l}\text { Component } \\
\text { of the } \\
\text { records }\end{array}$ & $\begin{array}{c}\text { RMSE between } \\
\text { simulated and observed } \\
\text { PGA records }\end{array}$ & $\begin{array}{l}\text { RMSE between } \\
\text { simulated and observed } \\
\text { response spectrum }\end{array}$ \\
\hline \multirow[t]{2}{*}{ IWTH25 } & \multirow[t]{2}{*}{03} & NS & 0.83 & 0.95 \\
\hline & & EW & 0.81 & 0.92 \\
\hline \multirow[t]{2}{*}{ IWTH26 } & \multirow[t]{2}{*}{12} & NS & 0.80 & 0.64 \\
\hline & & EW & 0.92 & 0.66 \\
\hline \multirow[t]{2}{*}{ AKTH04 } & \multirow[t]{2}{*}{22} & NS & 0.92 & 0.76 \\
\hline & & EW & 0.92 & 0.83 \\
\hline \multirow[t]{2}{*}{ IWTH24 } & \multirow[t]{2}{*}{22} & NS & 0.79 & 0.71 \\
\hline & & EW & 0.81 & 0.73 \\
\hline \multirow[t]{2}{*}{ MYGH02 } & \multirow[t]{2}{*}{27} & NS & 0.73 & 0.79 \\
\hline & & EW & 0.71 & 0.71 \\
\hline \multirow[t]{2}{*}{ AKTH06 } & \multirow[t]{2}{*}{34} & NS & 0.72 & 0.73 \\
\hline & & EW & 0.66 & 0.89 \\
\hline \multirow[t]{2}{*}{ IWTH20 } & \multirow[t]{2}{*}{38} & NS & 0.75 & 0.90 \\
\hline & & EW & 0.76 & 0.81 \\
\hline \multirow[t]{2}{*}{ AKTH19 } & \multirow[t]{2}{*}{40} & NS & 0.81 & 0.64 \\
\hline & & EW & 0.73 & 0.72 \\
\hline \multirow[t]{2}{*}{ IWTH05 } & \multirow[t]{2}{*}{45} & NS & 0.81 & 0.78 \\
\hline & & EW & 0.87 & 0.69 \\
\hline \multirow[t]{2}{*}{ IWTH04 } & \multirow[t]{2}{*}{47} & NS & 0.58 & 0.74 \\
\hline & & EW & 0.61 & 0.75 \\
\hline \multirow[t]{2}{*}{ MYGH04 } & \multirow[t]{2}{*}{47} & NS & 0.82 & 0.74 \\
\hline & & EW & 0.88 & 0.68 \\
\hline \multirow[t]{2}{*}{ IWTH19 } & \multirow[t]{2}{*}{49} & NS & 0.83 & 0.76 \\
\hline & & EW & 0.81 & 0.73 \\
\hline \multirow[t]{2}{*}{ IWTH22 } & \multirow[t]{2}{*}{50} & NS & 0.73 & 0.71 \\
\hline & & EW & 0.71 & 0.69 \\
\hline \multirow[t]{2}{*}{ IWTH27 } & \multirow[t]{2}{*}{56} & NS & 0.74 & 0.79 \\
\hline & & EW & 0.68 & 0.73 \\
\hline \multirow[t]{2}{*}{ MYGH11 } & \multirow[t]{2}{*}{70} & NS & 0.70 & 0.80 \\
\hline & & EW & 0.79 & 0.75 \\
\hline IWTH23 & 86 & NS & 0.81 & 0.81 \\
\hline & & EW & 0.73 & 0.74 \\
\hline
\end{tabular}

parameter (as discussed in equation 4) controls the duration of the acceleration envelope and can be calculated using the data recorded in the source area. Midorikawa (1989) suggested a generalised regression relation for the duration parameter and its linear form is given in equations (7a) and (7b):

$$
\begin{aligned}
& T_{\mathrm{d}}=0.0015 \times 10^{0.5 M}+a R^{b}, \\
& \log _{10}\left(T_{\mathrm{d}}-0.0015 \times 10^{0.5 M}\right) \\
& =b \log _{10}(R)+\log _{10}(a),
\end{aligned}
$$

where $R$ is the hypocentral distance in $\mathrm{km}$ and $M$ is the moment magnitude of small earthquake. In the above equation, one part is dependent on the size of the earthquake $(M)$ while the other, on the distance parameter $(R)$. Herein, we used three events $(M)$ 5.7, 5.4 and 5.3 recorded on 10, 6 and 9 stations, respectively, to estimate the coefficients ' $a$ ' (intercept) and ' $b$ ' (slope) as given in equation (7b) and figure 5 . The estimated $T_{\mathrm{d}}$ for the 2008 Iwate-Miyagi earthquake is given as

$$
T_{\mathrm{d}}=0.0015 \times 10^{0.5 M}+1.73 R^{0.26} .
$$

As far as the quality factor is taken into account, Kiyono (1992) described an average relation of the quality factor $Q(f)$ as $158 f^{0.7}$ for the Japan region. This relation has been successfully verified by Joshi and Midorikawa (2004) and therefore will be used here. 

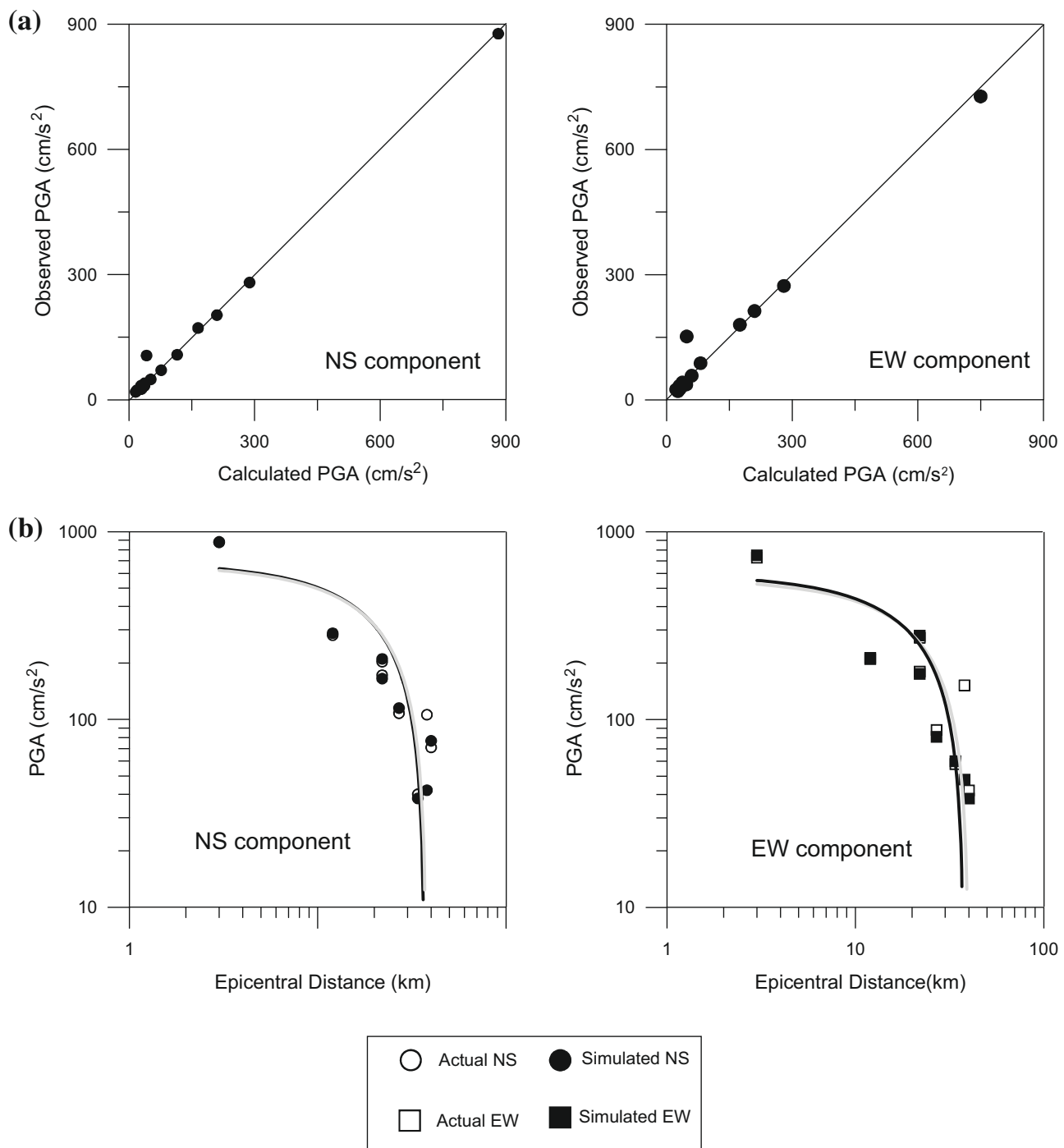

Figure 14. (a) Parametric comparison of NS and EW components of observed and simulated PGA and (b) plot of NS and EW components of observed and simulated PGA with respect to epicentral distance $(R)$ at IWTH25, IWTH26, AKTH04, IWTH24, MYGH02, AKTH06, IWTH20, AKTH19, IWTH05, IWTH04, MYGH04, IWTH19, IWTH22, IWTH27, MYGH11, IWTH23 stations. Black and grey lines show the attenuation characteristics of observed and simulated PGA values with epicentral distance $R$.

\section{Rupture model}

A primary component of the rupture model is to determine the dimensions of the rupture plane. In this context, the widely known Wells and Coppersmith (1994) relation is implemented to estimate the length and width of the rupture plane and calculated as 40 and $18 \mathrm{~km}$, respectively. Notably, the estimated rupture dimensions are in good agreement with Suzuki et al. (2010) and Hikima et al. (2008). Next, the strike, dip angle and depth of the rupture plane are determined by the Global CMT Harvard (available online, www.globalcmt.org) and found to be $\mathrm{N} 201^{\circ} \mathrm{E}, 48^{\circ}$ and $12 \mathrm{~km}$, respectively. On the basis of mainshock location and spatio-temporal distribution of aftershocks of this earthquake, the possible location of the rupture plane is estimated. Suzuki et al. (2010) have suggested a westward dipping plane for this earthquake. Recorded data for this earthquake suggests that the duration of a strong ground motion is surely less than expected. The duration of a highfrequency ground motion at one of the proximal stations, IWTH25 is about $7.1 \mathrm{~s}$. The rupture velocity of $2.87 \mathrm{~km} / \mathrm{s}$ for a $40-\mathrm{km}$ rupture length suggests the total duration of strong motion record as $13.94 \mathrm{~s}$. This unexpected small duration of strong motion record leads to the conclusion that only a small patch instead of the whole rupture plane is attributed to generate strong ground motion. Therefore, the present study describes the modelling of a small patch having an area of $18 \times 9 \mathrm{~km}^{2}$ within the rupture plane. This small patch is termed as SMGA and requires several 
parameters for modelling. Source displacement spectrum is used to calculate the SMGA parameters. A comparison between the observed and theoretical displacement spectrum of the recognised SMGAs in mainshock and aftershock at IWTH20 is illustrated in figure 6. Table 2 describes the estimated SMGA parameters from displacement spectra matching. As both the mainshock and aftershock recorded phases are clearly identifiable for IWTH20 station and they are considered for analysis.

Relying on the self-similarity relations of Kanamori and Anderson (1975), the rupture plane of SMGA is divided into $3 \times 3$ grids. For scaling, we considered one of the aftershock events $\left(M_{\mathrm{w}}\right.$ 4.8) as subfault (table 3). Based on the surface offset along a fault, the background seismicity of the region or the slip rate from GPS observations high slip rate area on the fault plane can be identified (Irikura and Miyake 2011). Furthermore, SMGA is identified on the basis of aftershock clusters in the rupture plane. Next, the proper selection of the nucleation point in the proposed SMGA is an important and challenging task. For this purpose, all possible positions of nucleation point are assumed in the SMGA. On the basis of minimum RMSE of waveform comparison at IWTH20 station, we confirm the nucleation point in the extreme western corner of the SMGA which agreed well with Suzuki's (2010) suggestion of a westward dipping plane for this earthquake (figure 7). Moreover, the identified location of the nucleation point also justifies Kato's (2012) suggestion where he proposed that stress found to be concentrated near the deeper edge of the plane and when it exceeds the fracture energy, rupture propagates. The estimated parameters of SMGA are summarised in table 4 and the final estimated rupture model with SMGA is shown in figure 8 . The velocity model of Ukawa et al. (1984) is used (table 5) and the rupture is positioned in the fourth layer of the velocity model at a depth of 12 km (figure 9).

\section{Strong motion simulation of the 2008 Iwate-Miyagi earthquake}

Strong motion records were simulated at 16 near-field stations using estimated SMGA parameters and MSET (figures 10 and 11). Furthermore, pseudo-acceleration spectra were obtained from the simulated and observed acceleration records with $5 \%$ damping (figures 12 and 13). A comparable match between simulated and observed data was found for all stations except a few ones. This may be due to the factors like local inhomogeneities, frequency-based attenuation of the energy. A brief comparison between simulated and observed records is summarised in table 6 . A variation of simulated and observed PGA and its attenuation with epicentral distance is shown in figure 14 .

\section{Discussion}

As we mentioned earlier, the intriguing basis of the 2008 Iwate-Miyagi earthquake was the largest PGA observed at IWTH25 station. Therefore, the relationship between the rupture process and recorded PGA values is a matter of significant attention. This analysis reveals that the highest PGA phase occurs during the initial $2-3 \mathrm{~s}$ of the total record duration at IWTH25 station. This suggests that the particular phase is generated from a patch on the rupture plane that is the first to rupture. This patch with a high slip rate is referred to as SMGA and is identified just below IWTH25 station. This evidence highly supports our estimated source model using MSET.

\section{Conclusions and future scope}

We estimated the source model of the 2008 Iwate-Miyagi ( $\left.M_{\mathrm{w}} 6.9\right)$ earthquake using MSET. The technique provides one SMGA in the rupture plane and nucleation point in the extreme western corner of SMGA. Using estimated rupture plane with one SMGA strong motion records are simulated at 16 proximal stations. A similar match between the simulated and observed waveforms in both the frequency and time domains is observed. The quantitative analysis suggests an almost linear fit for PGA values of these waveforms. Moreover, the attenuation rate of these PGA values with epicentral distance follows the similar trend. These results confirm the reliability of MSET and estimated source model of this earthquake. Therefore, we believe that the present study will be highly useful for seismic hazards analysis and modelling future earthquakes in this region.

\section{Acknowledgements}

Sandeep is grateful to Prof N P Singh for his valuable suggestions and the Department of 
Geophysics, Banaras Hindu University, Varanasi for providing the basic research facility. Dr Preeti is thankfully acknowledged for her efforts on improving the quality of manuscript. Data employed in this work were obtained from the KiKnet (website http://www.k-net.bosai.go.jp/k-net/ and USGS (website http://www.usgs.gov/). This research work is a result of the sponsored project ECR/2016/000737 from the Science and Engineering Research Board, DST. PK acknowledges the director of Wadia Institute of Himalayan Geology, Dehradun.

\section{References}

Aki K 1967 Scaling law of seismic spectrum; J. Geophys. Res. 72 1217-1231.

Asano K and Iwata T 2012 Source model for strong ground motion generation in $0.1-10 \mathrm{~Hz}$ during the 2011 Tohoku earthquake; Earth Planet. Space 64(12) 1111-1123.

Boore D M 1983 Stochastic simulation of high frequency ground motion based on seismological models of radiated spectra; Bull. Seismol. Soc. Am. 73 1865-1894.

Boore D M and Bommer J 2005 Processing of strong motion accelerograms: Needs, options and consequences; Soil Dyn. Earthq. Eng. 25 93-115.

Brune J N 1970 Tectonic stress and spectra of seismic shear waves from earthquakes; J. Geophys. Res. $\mathbf{7 5}$ 4997-5009.

Hikima K, Miyazaki S and Koketsu K 2008 Rupture process of the 2008 Iwate-Miyagi Nairiku Earthquake (Mj 7.2), Japan; inferred from strong motion and geodetic data, American Geophysical Union, Fall Meeting 2008, abstract id. S51D-1789.

Irikura K and Kamae K 1994 Estimation of strong ground motion in broad-frequency band based on a seismic source scaling model and an empirical Green's function technique; Ann. Geofis. XXXVII(6) 1721-1743.

Irikura K, Kagawa T and Sekiguchi H 1997 Revision of the empirical Green's function method by Irikura, 1986; Programme and Abstracts, The Seismological Society of Japan, Vol. 2, B25p.

Irikura K and Miyake H 2011 Recipe for predicting strong ground motion from crustal earthquake scenarios; Pure Appl. Geophys. 168 85-104.

Joshi A 2001 Strong motion modeling of the source of the Chamoli earthquake of March 29, 1999 in the Garhwal Himalaya, India; J. Seismol. 5 499-518.

Joshi A 2004 A simplified technique for simulating wide band strong ground motion for two recent Himalaya earthquakes; Pure Appl. Geophys. 161 1777-1805.

Joshi A and Patel R C 1997 Modelling of active lineaments for predicting a possible earthquake scenario around Dehradun, Garhwal Himalaya, India; Tectonophys. 283 289-310.

Joshi A, Kumar B, Sinvhal A and Sinvhal H 1999 Generation of synthetic accelerograms by modelling of rupture plane; J. Earthq. Technol. 36 43-60.
Joshi A, Singh S and Giroti K 2001 The simulation of ground motions using envelope summations; Pure Appl. Geophys. 158 877-901.

Joshi A and Midorikawa S 2004 A simplified method for simulation of strong ground motion using rupture model of the earthquake source; J. Seismol. 8 467-484.

Joshi A, Kumari P, Sharma M L, Ghosh A K, Agarwal M K and Ravikiran A 2012a A strong motion model of the 2004 great Sumatra earthquake: Simulation using a modified semi empirical method; J. Earthq. Tsunami 6 1-29.

Joshi A, Kumari P, Singh S and Sharma M L 2012b Near-field and far-field simulation of accelerograms of Sikkim earthquake of September 18, 2011 using modified semi-empirical approach; Nat. Hazards 64 1029-1054.

Joshi A, Sandeep and Kamal 2014 Modeling of strong motion generation areas of the 2011 Tohoku, Japan earthquake using modified semi empirical technique; Nat. Hazards $\mathbf{7 1}$ 587-609.

Joshi A, Kuo C H, Dhibar P, Sandeep, Sharma M L, Wen K L and Lin C M 2015 Simulation of the records of the 27th March 2013, Nantou Taiwan earthquake using modified semi-empirical approach; Nat. Hazards 78 995-1020.

Kamae K and Kawabe H 2004 Source model composed of asperities for the 2003 Tokachi-oki, Japan, earthquake $(\mathrm{MJMA}=8.0)$ estimated by the empirical Green's function method; Earth Planet. Space 56 323-327.

Kameda H and Sugito M 1978 Prediction of strong earthquake motions by evolutionary process model; In: Proceedings of the sixth Japan earthquake engineering symposium, pp. 41-48.

Kanamori H and Anderson D L 1975 Theoretical basis of some empirical relations in seismology; Bull. Seismol. Soc. Am. 65 1073-1095.

Kato N 2012 Dependence of earthquake stress drop on critical slip-weakening distance; J. Geophys. Res. 117 1-10.

Kiyono J 1992 Identification and synthesis of seismic ground motion in structural response analysis; $\mathrm{PhD}$ Thesis, Department of Civil Engineering Kyoto University.

Kumar D, Teotia S S and Khattari K N 1997 The representation of attenuation characterstics of strong ground motion observed in the 1996 Dharamshala and 1991 Uttarkasshi earthquakes by available empirical relations; Curr. Sci. 73 543-548.

Kumar R, Sumathi P and Kumar A 2016 A time-frequency approach for generation of synthetic time-histories of earthquake signals, Springer; Acta Geodaet. Geophys. 51(1) 57-67.

Kurahashi S and Irikura K 2011 Source model for generating strong ground motions during the 2011 off the Pacific coast of Tohoku earthquake; Earth Planet. Space 63 571-576.

Midorikawa S 1989 Synthesis of ground acceleration of large earthquakes using acceleration envelope waveform of small earthquake; J. Struct. Construct. Eng. 398 23-30.

Midorikawa S 1993 Semi empirical estimation of peak ground acceleration from large earthquakes; Tectonophys. 218 287-295.

Miyahara M and Sasatani T 2004 Estimation of source process of the 1994 SanrikuHaruka-oki earthquake using empirical Green's function method; Geophys. Bull. Hokkaido Univ. Sapporo Japan 67 197-212 (in Japanese with English abstract).

Miyake H, Iwata T and Irikura K 1999 Strong ground motion simulation and source modeling of the Kagoshima-ken 
Hokuseibu earthquakes of March 26 (MJMA 6.5) and May 13 (MJMA 6.3), 1997, using empirical Green's function method; Zisin 51 431-442.

Miyake H, Iwata T and Irikura K 2001 Estimation of rupture propagation direction and strong motion generation area from azimuth and distance dependence of source amplitude spectra; Geophys. Res. Lett. 28(14) 2727-2730.

Miyake H, Iwate T and Irikura K 2003 Source characterization for broadband ground-motion simulation: Kinematic heterogeneous source model and strong motion generation area; Bull. Seismol. Soc. Am. 93 2531-2545.

Sandeep, Joshi A, Kamal, Kumar P and Kumar A 2014a Effect of frequency dependent radiation pattern in simulation of high frequency ground motion of Tohoku earthquake using modified semi empirical method; Nat. Hazards 73 1499-1521.

Sandeep, Joshi A, Kamal, Kumar P and Kumari P 2014b Modeling of strong motion generation area of the Uttarkashi earthquake using modified semi-empirical approach; Nat. Hazards 73 2041-2066.

Sandeep, Joshi A, Kamal, Kumar P, Kumar A and Dhibar P 2015 Modeling of strong motion generation areas of the Niigata, Japan, earthquake of 2007 using modified semi empirical technique; Nat. Hazards 77 933-957.

Sandeep, Joshi A, Kumari P, Lal S, Vandana, Kumar P and Kamal 2017a Emergence of the semi-empirical technique of strong ground motion simulation: A review; J. Geol. Soc. India 89 719-722.

Sandeep, Joshi A, Sah S K, Kumar P, Lal S, Vandana, Kamal and Singh R S 2017b Source model estimation of the 2005 Kyushu earthquake, Japan using modified semi empirical technique; J. Asian Earth Sci. 147 240-253.
Sandeep, Joshi A, Lal S, Kumar P, Vandana, Sah S K and Kamal 2017c Simulation of strong ground motion of the 2009 Bhutan earthquake using modified semi empirical technique; Pure Appl. Geophys. 174 4343-4356.

Sandeep, Joshi A, Sah S K, Kumar P, Lal S and Kamal 2019 Modelling of strong motion generation areas for a great earthquake in central seismic gap region of Himalayas using the modified semi-empirical approach; J. Earth Syst. Sci., https://doi.org/10.1007/s12040-019-1126-5.

Seismosoft 2002 SeismoSignal-A computer program for signal processing of time-histories; www.seismosoft.com.

Suzuki W and Iwata T 2007 Source model of the 2005 MiyagiOki, Japan, earthquake estimated from broadband strong motions; Earth Planet. Space 59 1155-1171.

Suzuki W, Aoi S and Sekiguchi H 2010 Rupture process of the 2008 Iwate-Miyagi Nairiku, Japan, earthquake derived from near-source strong-motion records; Bull. Seismol. Soc. Am. 100(1) 256-266.

Takiguchi M, Asano K and Iwate T 2011 The comparison of source models of repeating subduction-zone earthquakes estimated using broadband strong motion records-1982 and 2008 Ibaraki-ken-oki M7 earthquakes; J. Seismol. Soc. Japan 63 223-242 (in Japanese with English abstract).

Ukawa M, Ishida M, Matsumura S and Kasahara K 1984 Hypocenter determination method of the Kanto-Tokai observational network for microearthquakes; Rep. Nat'l. Res. Cent. Disaster Prev. 53 1-88 (in Japanese with English abstract).

Wells L D and Coppersmith K J 1994 New empirical relationships among magnitude, rupture length, rupture width, rupture area and surface displacement; Bull. Seismol. Soc. Am. 84 974-1002. 